\title{
Avaliação de políticas públicas de educação: uma análise da eficácia do programa nacional de tecnologia educacional (Proinfo) no município de Gurupi (TO)
}

\section{RESUMO}

Roberto Nunes Rodrigues rrodrigues68@gmail.com Mestre em Gestão de Políticas Públicas

Universidade Federal do Tocantins (UFT)

Mônica Aparecida da Rocha Silva monicars@uft.edu.br

Doutora em Ciências Sociais (UNB)

Professora da Universidade Federal do Tocantins (UFT)
Este trabalho tem como objetivo analisar a eficácia do Programa Nacional de Tecnologia Educacional (Prolnfo), no que concerne à inclusão digital e ao apoio pedagógico, em escolas do Ensino Fundamental, nos anos finais, no Município de Gurupi (Tocantins). A abordagem metodológica adotada neste trabalho é quali-quanti. A coleta de dados foi realizada por meio da aplicação de questionários a uma amostra de estudantes do 60 ao 9o ano do Ensino Fundamental e de entrevistas semiestruturadas com o secretário de Educação, professores e diretores de seis escolas do Município de Gurupi. Ao avaliar a eficácia do Prolnfo no Município de Gurupi (TO), é possível concluir que o Programa está sendo parcialmente eficaz, pois não cumpre, plenamente, os seus objetivos originais, a saber: proporcionar a inclusão digital e servir de ferramenta de apoio pedagógico.

PALAVRAS-CHAVE: Prolnfo. Avaliação de Políticas Públicas. Educação Fundamental. 


\section{INTRODUÇÃO}

Este trabalho tem o objetivo de analisar a eficácia do Programa Nacional de Tecnologia Educacional (Prolnfo), no que concerne à inclusão digital e ao apoio pedagógico, em escolas do Ensino Fundamental, nos anos finais, no Município de Gurupi (Tocantins).

A Constituição Federal do Brasil (BRASIL, 1988), em seu Art. 211, § 20, determina que os municípios atuem prioritariamente no Ensino Fundamental e na Educação Infantil. Segundo previsão na Lei de Diretrizes e Bases da Educação - LDB (BRASIL, 1996) - , a educação básica compreende a Educação Infantil, o Ensino Fundamental e o Ensino Médio. A mesma lei prevê que a educação básica é de caráter obrigatório e gratuito dos 4 aos 17 anos de idade.

A implementação do Programa Nacional de Tecnologia Educacional (Prolnfo) vem ocorrendo de forma descentralizada, existindo em cada unidade da Federação uma Coordenação Estadual e os Núcleos de Tecnologia Educacional (NTE), dotados de infraestrutura de informática e comunicação, que reúnem educadores e especialistas em tecnologia de hardware e software (BRASIL, 2018). A partir de 12 de dezembro de 2007, o Prolnfo passou a ter como principal objetivo promover o uso pedagógico das tecnologias de informação e comunicação nas redes públicas de educação básica.

É de grande importância analisar o funcionamento do Prolnfo, uma vez que se constata que a tecnologia mudou a forma de ensinar. Os professores, nesse contexto, precisam ter domínio das novas ferramentas educacionais para aplicálas em sala de aula. Porém, os alunos, muitas vezes, são "bombardeados" diariamente com muitas inovações tecnológicas. É preciso, então, utilizar esta ferramenta inovadora para estimular o aprendizado e não desestimular o aluno.

O Programa Nacional de Tecnologia Educacional -Prolnfo - é uma política pública de Educação, que foi criada pelo Ministério da Educação por meio da Portaria no 522 em 9 de abril de 1997 com a finalidade de promover o uso da tecnologia como ferramenta de enriquecimento pedagógico no ensino público Fundamental e Médio (BRASIL, 2018). Nesse sentido, cabe esclarecer que, com as ações do Prolnfo, não existe a pretensão de enfrentar estruturalmente o problema da desigualdade de oportunidades educacionais existente no país. As mazelas históricas da educação não podem ser resolvidas, senão por um conjunto de ações articuladas, que fogem ao alcance de uma política de inclusão digital, como é o caso do Programa em discussão.

Desta forma, este trabalho se propõe a responder ao seguinte questionamento: em que medida o Prolnfo vem se constituindo em um instrumento de inclusão digital e de apoio pedagógico em escolas do Ensino Fundamental, nos anos finais, do município de Gurupi (TO)?

\section{METODOLOGIA}

A abordagem metodológica adotada neste trabalho é quali-quanti. A pesquisa qualitativa responde a questões muito particulares, tendo preocupação, 
nas Ciências Sociais, com um nível de realidade que não pode ser quantificado. Desse modo, ela trabalha com vários significados, motivos, crenças, valores e atitudes, o que propicia um espaço mais profundo das relações, dos processos e dos fenômenos, que não podem ser reduzidos a meras variáveis (MINAYO, 2001). Nesta pesquisa, o método quantitativo complementou o qualitativo.

A coleta de dados foi realizada por meio de aplicação de questionários a uma amostra de estudantes do 60 ao 9o ano do Ensino Fundamental, englobando todas as escolas que atendem a esse nível, e de entrevistas semiestruturadas com o secretário de Educação, professores e diretores de seis escolas do município de Gurupi.

As entrevistas foram transcritas e analisadas de acordo com os parâmetros da análise de conteúdo. Para Bardin (2011, p. 47), o termo análise de conteúdo designa um conjunto de técnicas de análise das comunicações que visam obter, por procedimentos sistemáticos e objetivos de descrição do conteúdo das mensagens, indicadores (quantitativos ou não) que permitam a inferência de conhecimentos relativos às condições de produção/recepção (variáveis inferidas) destas mensagens.

A pesquisa bibliográfica e documental e a aplicação de questionários e realização de entrevistas semiestruturadas foram realizadas nos anos de 2017 e 2018. O trabalho de coleta em campo, entrevistas e questionários, foi realizado no primeiro semestre de 2018.

Os locais de pesquisa foram a Secretaria de Educação do Município de Gurupi e $100 \%$ das escolas que atendem aos anos finais do Ensino Fundamental: E.M. Antônio de Almeida Veras, E.M. Professora Ilsa Borges Vieira, E.M. Lenival Correia Ferreira, E.M. Gilberto Rezende Rocha Filho, E.M. Ulisses Guimarães e E.M. Odair Lucio. As entrevistas realizadas perfazem um total de 14 (quatorze), a saber: 1(um) secretário de Educação; 3 (três) diretores; 3 (três) coordenadores; 3 (três) gestores; e 4 (quatro) professores. Foram aplicados218 (duzentos e dezoito) questionários a um universo de 1.495 (um mil, quatrocentos e noventa e cinco) alunos dos anos finais do Ensino Fundamental (EF II).

Por meio dessa amostra, foi possível obter os dados que embasaram a pesquisa sobre a eficácia do Programa Nacional de Tecnologia Educacional (Prolnfo) no Município de Gurupi (TO). Por intermédio das entrevistas, foi aferida a percepção de diretores, gestores e professores sobre tal eficácia. Além disso, por meio de questionários aplicados aos alunos do 60 ao 90 ano, buscou-se mapear o perfil socioeconômico dos estudantes e identificar suas necessidades e realidade em relação ao uso de computadores e internet, tanto na escola como em sua vida familiar. O trabalho de pesquisa de campo trouxe à tona uma realidade só perceptível a quem verifica in loco o funcionamento de um Programa governamental em uma escola pública.

A fim de avaliar a eficácia do Prolnfo no que tange à inclusão digital e ao apoio pedagógico em escolas do Ensino Fundamental, nos anos finais, no Município de Gurupi (TO), a análise dos resultados foi realizada com base nas seguintes categorias: capacitação, condições de infraestrutura e manutenção dos laboratórios e utilização dos laboratórios pelos professores.

Como forma de se comparar este trabalho com outros estudos sobre o mesmo objeto, foi feito um levantamento que possibilitou algumas conclusões. 
Como demonstrado no quadro 1 , verificamos o quanto o tema tem sido abordado nos últimos anos. Trata-se de trabalhos desenvolvidos nos últimos cinco anos e cada um tem uma característica conforme as peculiaridades de cada autor, com um enfoque próprio. Entretanto, todos estão de alguma forma abordando o Prolnfo ou as tecnologias educacionais.

Quadro 1- Dissertações sobre o Prolnfo, de 2013 a 2017, e principais conclusões

\begin{tabular}{|c|c|c|}
\hline Tipo/Título & Autor & Principais Conclusões \\
\hline $\begin{array}{l}\text { Dissertação: Avaliação de } \\
\text { Política Pública: O Prolnfo } \\
\text { e sua gestão no Município } \\
\text { de Parnamirim-RN. }\end{array}$ & $\begin{array}{l}\text { Maria das } \\
\text { Vitórias } \\
\text { Ferreira da } \\
\text { Rocha }\end{array}$ & $\begin{array}{l}\text { Constatou-se que o Prolnfo necessita de } \\
\text { avaliações periódicas, por parte dos } \\
\text { órgãos gestores do programa, acerca das } \\
\text { ações desenvolvidas. }\end{array}$ \\
\hline $\begin{array}{l}\text { Dissertação: Um olhar } \\
\text { sobre a implantação do } \\
\text { Prolnfo em escolas } \\
\text { municipais de Minas } \\
\text { Gerais. }\end{array}$ & $\begin{array}{c}\text { Vânia de } \\
\text { Fátima } \\
\text { Flores Paiva }\end{array}$ & $\begin{array}{l}\text { Os resultados evidenciaram que o } \\
\text { Prolnfo, mesmo após a reformulação } \\
\text { promovida em } 2007 \text { e a ampliação nos } \\
\text { investimentos, ainda não alcançou seus } \\
\text { objetivos e foram poucos os efeitos } \\
\text { significativos, principalmente no ensino. }\end{array}$ \\
\hline $\begin{array}{l}\text { Dissertação: Panorama de } \\
\text { Política Pública Federal } \\
\text { entre escolas públicas e } \\
\text { TIC: estudos sobre Prolnfo, } \\
\text { Prouca, PBLE. }\end{array}$ & $\begin{array}{c}\text { Luiz Alberto } \\
\text { Menezes } \\
\text { Cerqueira }\end{array}$ & $\begin{array}{l}\text { A política pública brasileira para a } \\
\text { integração de tecnologias e escolas } \\
\text { públicas deve seguir ampliando a } \\
\text { disponibilidade de recursos em } \\
\text { tecnologia digital, visto que quantidade } \\
\text { significativa de escolas brasileiras ainda } \\
\text { não dispõe de qualquer recurso. }\end{array}$ \\
\hline $\begin{array}{l}\text { Dissertação: Inclusão } \\
\text { Digital e Educação: uma } \\
\text { avaliação do Prolnfo em } \\
\text { Sobral/CE. }\end{array}$ & $\begin{array}{l}\text { Antonia } \\
\text { Zeneide } \\
\text { Rodrigues }\end{array}$ & $\begin{array}{l}\text { Embora a política apresente algumas } \\
\text { características de um modelo } \\
\text { educacional para a sociedade em rede, } \\
\text { ela ainda utiliza as TIC de modo } \\
\text { secundário na efetivação do direito à } \\
\text { educação. }\end{array}$ \\
\hline
\end{tabular}

Fonte: Elaboração própria com base nas informações dos sites da CAPES e Banco de Teses e Dissertações (BDTD)

\section{DESENVOLVIMENTO (RESULTADOS E DISCUSSÕES)}

\section{As tecnologias informacionais na educação}

Mitchel(1999) afirma que nas Tecnologias da Informação e Comunicação (TICS) existem interdependências mútuas: a internet precisa do computador pessoal e o computador pessoal precisa da internet. Um dos principais conceitos elencados pelo autor é a emergência de um espaço de fusão. De acordo com o autor, esse seria um espaço arquitetônico no qual as tecnologias digitais eletrônicas permitiriam combinações de pessoas e atividades. Ainda sobre o espaço de fusão, ele cita o exemplo de um ônibus escolar que utilize o sistema GPS (Global Positioning System)de informação geográfica para receber e dar informações sobre as zonas por aonde vai passando. Nesse exemplo, a Geografia, 
História, Ecologia e a sala de aula estariam se fundindo com o transporte e espaço público. Neste contexto, muda-se a forma como se aprende.

Destarte, é esse espaço de fusão que torna o ambiente propício ao desenvolvimento de novas habilidades e percepções, em oposição a outros tempos em que o sistema poderia ser considerado monótono, ou seja, quando inexistiam as possibilidades de múltiplas informações. Pode-se, então, afirmar que este tipo de tecnologia, que permite múltiplas combinações, é denominado tecnologia informacional.

Segundo Castells (1999), o desenvolvimento das tecnologias informacionais propiciou um novo modo de desenvolvimento, o informacional, fomentado pela tecnologia de geração de conhecimento, de processamento de informação e de comunicação de símbolos. Esse modo informacional é caracterizado pela ação de conhecimentos sobre o próprio conhecimento, como principal fonte de produtividade. Esse tipo de ação diz respeito ao fato de que a tecnologia digital se encontra em permanente mudança, com novos softwares e hardwares sendo inventados ou reinventados a todo instante. Essa rápida transformação repercute nas formas de se portar na sociedade, de uma maneira geral, e de produzir conhecimento.

O autor destaca, ainda, que a revolução informacional e a reestruturação capitalista fazem surgir uma nova economia, que pode ser informacional e global. Informacional porque depende da capacidade dos agentes econômicos (empresas, regiões, nações); global porque o consumo e a circulação, bem como seus componentes (capital, trabalho, matéria-prima, administração, informação, tecnologia, mercados), estão organizados em escala global, diretamente ou mediante uma rede de conexões entre agentes econômicos (CASTELLS, 1999).

Neste contexto, mudam as relações de tempo e espaço escolares, assim como as relações entre professores e alunos e dos alunos entre si. Segundo Loureiro e Lopes $(2015$, p.3), no século XXI, estar incluído digitalmente é condição mínima para a participação em uma sociedade em rede e para que estejamos conectados a outras formas de trabalho, de relacionamento e de participação política, social, cultural e econômica. Dessa forma, assegurar que todos tenham acesso ao mundo digital é condição necessária, embora não suficiente, para garantir condições de forma que em um futuro próximo tenhamos, em diferentes escalas de participação, uma população conectada e acessível às capturas digitais.

É preciso dar oportunidade para que todas as pessoas tenham acesso a esse mundo cada vez mais digital e cada vez mais conectado. No campo educacional, o Brasil ainda tem muito a evoluir, mas ao olhar para trás é possível verificar que muito já foi feito, bastando melhorar o que existe e ajustar condutas.

O trabalho de Loureiro e Lopes (2015) busca, justamente, evidenciar como os usos e a disseminação das Tecnologias Digitais (TD), por meio da escola, constituem formas cada vez mais sofisticadas e inclusivas de captura dos indivíduos, para um tipo de racionalidade governamental contemporânea. A Tecnologia, segundo as referidas autoras, é como uma dimensão estratégica das práticas, e as tecnologias e/ou técnicas seriam"os meios calculados" pelos quais uma ação qualquer poderá atingir certos fins ou objetivos. 
Desse modo, as políticas governamentais, nos dias atuais, devem contemplar as TD nas escolas, visando incluir digitalmente os alunos na sociedade. Essas políticas poderão surtir efeito se forem administradas com eficiência pelas escolas; caso contrário, o alcance dos objetivos pode ser comprometido, por não haver planejamento e execução adequados. Por isso, é preciso romper com o modelo concentrador de gestão, pois estamos cientes de que esse modelo não é uma fatalidade histórica, um fenômeno natural diante do qual só nos resta nos precavermos. São muitas as evidências que indicam, de forma clara e convincente, que é pela via de uma educação inclusiva e democrática que se poderá garantir que as novas tecnologias da informação e da comunicação cumpram seu papel social, gerando melhor qualidade de vida para o conjunto da população (WAISELFISZ, 2007, p.10).

A educação inclusiva e democrática tem como principal finalidade alcançar todos os extratos da sociedade, sem nenhum tipo de exceção. Não se admite criança fora da escola, seja ela negra, indígena, com necessidades especiais ou qualquer outra. As leis educacionais são feitas para garantir o direito de estudar, restando a toda a sociedade fazer com que essas leis sejam cumpridas. As TIC são importantes nessa educação inclusiva e democrática, pois elas fazem com que se atinjam mais pessoas ao mesmo tempo, principalmente com o advento das redes sem fio.

Loureiro e Lopes (2015) ressaltam que a formação dos professores é outro aspecto imprescindível na implantação das TIC na educação e que esta deve acontecer continuamente, no contexto do trabalho escolar. As TIC (Tecnologias de Informação e Comunicação) trazem mudanças para a prática docente, o que impõe a necessidade de repensar a formação de professores, não somente dando-lhes ferramentas como laptops, mas principalmente transformando os espaços educativos e garantindo processos de formação continuada. Este fim já é assegurado no Inciso III do Art. 40 do Decreto no 6.300, de 12 de dezembro de 2007, que dispõe sobre o Programa Nacional de Tecnologia Educacional Prolnfo -, como se pode notar: "III - assegurar recursos humanos e condições necessárias ao trabalho de equipes de apoio para o desenvolvimento e acompanhamento das ações de capacitação nas escolas" (BRASIL, 2007).

O Prolnfo, ao abordar os objetivos das TIC, cita o direito de todos à cidadania, que, na perspectiva das políticas, se efetivaria pela inclusão e pelo acesso às tecnologias de informação e comunicação. Estas tecnologias seriam as ferramentas capazes de instrumentalizar professores e alunos para "enfrentar estruturalmente a desigualdade de oportunidades educacionais".

Lévy (1999) relata os impactos das tecnologias sobre a construção da inteligência coletiva, que seria a inteligência de um grupo, de um estado ou país. O autor a chama de "veneno e remédio" da cibercultura. Segundo ele, dessa influência surge uma nova relação com o saber, que nada mais é do que professores e alunos articulando-se em torno desse novo modelo de aprendizado, em que o tempo e o espaço são diferentes do que havia no modelo clássico.

Essa nova relação implica um novo fazer no qual as partes envolvidas precisam estar aptas a fazer uso pedagógico das TIC. Professores necessitam de capacitação para estar aptos para esse uso. E os alunos precisam conhecer, entender e aceitar orientações, para que possam aprender a não só usá-las para 
diversão, mas sim como ferramentas cognitivas, capazes de aprimorar e acelerar seu desenvolvimento intelectual.

É preciso haver reflexão sobre os sistemas de educação, pois, Segundo Lévy (1999), o novo fazer exige capacitação, atualização e pré-disposição dos governantes e gestores em propiciar essas necessidades. $O$ autor prossegue afirmando que, com o advento do ciberespaço, um novo lugar de troca de conhecimentos, o saber, deve articular-se à nova perspectiva de educação.

Ademais, há necessidade de renovação dos saberes, pois a nova configuração do mundo do trabalho e o ciberespaço tornam os processos tradicionais de aprendizagem obsoletos.Dessa forma, quem insiste em praticar um ensino baseado somente na transmissão/recepção corre o risco de estagnarse profissionalmente. As práticas pedagógicas devem ser repensadas em face do contexto do ciberespaço.

Sobre os professores, Lévy (1997) afirma que as novas exigências da sociedade atual levam as instituições de formação de professores a se reposicionarem para atender às diferentes metodologias, tudo numa perspectiva da economia do saber. As universidades e faculdades, que hoje formam inúmeros professores pelo Brasil afora, precisam estar atentas ao conteúdo de seus cursos no sentido de proporcionarem uma formação adequada aos novos tempos, simulando ambientes em que a tecnologia possa ser aplicada e preparando o professor para o uso adequado dessas tecnologias.

Percebe-se que é importante investir na formação de professores, sobretudo nos anos iniciais, bem como no que diz respeito ao uso das Novas Tecnologias de Informação e Comunicação (NTIC) como ferramentas pedagógicas.

\section{A escola e a inclusão digital: o caso do Prolnfo em Gurupi (TO)}

Neste tópico, iremos discutir o Prolnfo em Gurupi, com o intuito de dar resposta à seguinte questão: em que medida o referido Programa vem se constituindo em um instrumento de inclusão digital e de apoio pedagógico em escolas do Ensino Fundamental, nos anos finais, do município de Gurupi (TO)?

A Portaria no 522, de 9 de abril de 1997, do Ministério da Educação e Cultura (MEC), criou o nominado Programa Nacional de Informática na Educação Prolnfo -, que estabeleceu o seguinte:

Art. 10 Fica criado o Programa Nacional de Informática na Educação -Prolnfo, com a finalidade de disseminar o uso pedagógico das tecnologias de informática e telecomunicações nas escolas públicas de Ensino Fundamental e médio pertencentes às redes estadual e municipal.

Em 2007, houve mudanças nas diretrizes do Programa, sendo editado o Decreto no 6.300, de 12 de dezembro de 2007, que mudou o nome do Programa para Programa Nacional de Tecnologia Educacional - Prolnfo - e que definiu de maneira pontual os objetivos do programa, conforme texto a seguir: 
Art. 1ㅇ O Programa Nacional de Tecnologia Educacional - Prolnfo, executado no âmbito do Ministério da Educação, promoverá o uso pedagógico das tecnologias de informação e comunicação nas redes públicas de educação básica.

Parágrafo único. São objetivos do Prolnfo:

I - promover o uso pedagógico das tecnologias de informação e comunicação nas escolas de educação básica das redes públicas de ensino urbanas e rurais;

II - fomentar a melhoria do processo de ensino e aprendizagem com o uso das tecnologias de informação e comunicação;

III - promover a capacitação dos agentes educacionais envolvidos nas ações do Programa;

IV - contribuir com a inclusão digital por meio da ampliação do acesso a computadores, da conexão à rede mundial de computadores e de outras tecnologias digitais, beneficiando a comunidade escolar e a população próxima às escolas;

V - contribuir para a preparação dos jovens e adultos para o mercado de trabalho por meio do uso das tecnologias de informação e comunicação; e

VI - fomentar a produção nacional de conteúdos digitais educacionais.

Art. 2ㅇ O Prolnfo cumprirá suas finalidades e objetivos em regime de colaboração entre a União, os Estados, o Distrito Federal e os Municípios, mediante adesão.

Tendo como referência os objetivos do Programa explicitados anteriormente, percebeu-se, com base na pesquisa realizada, que há um comprometimento dos gestores escolares em manter uma boa qualidade de ensino, mesmo mediante as adversidades existentes. No município, os professores devem incluir, em seu planejamento de aulas, a utilização dos meios tecnológicos à disposição, seja em sala de aula ou no laboratório.

Entretanto, ainda é perceptível a falta de capacitação dos professores para a utilização dos meios tecnológicos à disposição de maneira mais abrangente e impactante na aprendizagem dos alunos. As escolas não dispõem de um Núcleo de Tecnologia Educacional (NTE) próprio para, entre outras finalidades, resolver problemas relacionados aos computadores e à internet. Tudo fica centralizado na Secretaria de Educação, onde existe uma pequena equipe que não consegue resolver os problemas de todas as escolas de acordo com as demandas existentes. Além disso, segundo relato dos diretores entrevistados, há uma reação de resistência de alguns professores a utilizar os laboratórios, que pode se dar por falta de capacitação.

No estudo completo foram determinadas 10 (dez) categorias a serem analisadas para se aferir a eficácia do Prolnfo em Gurupi (TO). A seguir, serão discutidos os dados coletados nas entrevistas, a partir das três categorias mais importantes para a análise da eficácia do Prolnfo em Gurupi, que são: 
capacitação, condições de infraestrutura e manutenção dos laboratórios e utilização dos laboratórios pelos professores, como consta no Gráfico 1.

Por meio do mesmo gráfico, é possível também avaliar o quanto as categorias podem apontar respostas à questão norteadora deste artigo. Em outras palavras, o quanto os participantes do Prolnfo percebem o alcance ou o distanciamento da sua eficácia nas escolas.

Gráfico 1 - Categorias de análise

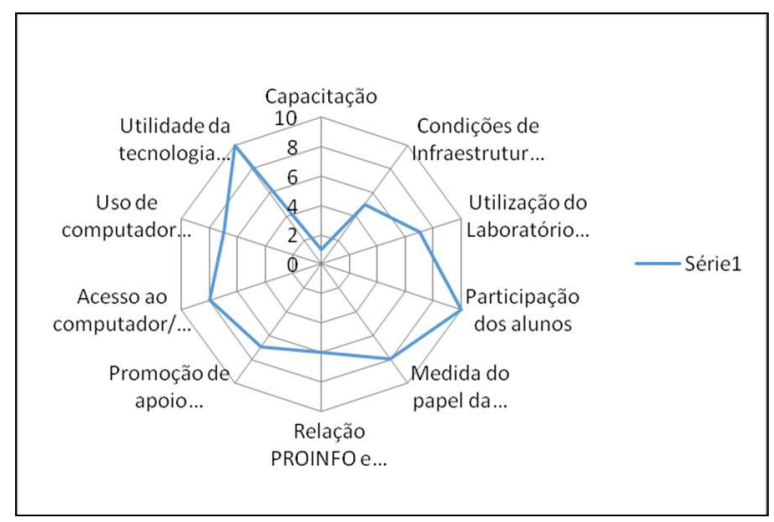

Fonte: Elaboração própria

\section{Capacitação}

A capacitação é uma das mais importantes condições para o sucesso do Prolnfo; entretanto, percebe-se pelas entrevistas que nenhum dos professores entrevistados fez os cursos de capacitação oferecidos pelo programa, como relatado pelo entrevistado E3: "nunca fiz nenhum tipo de curso de capacitação oferecido pelo Prolnfo, mas pretendo fazer". Outros até mesmo não lembram mais, pois faz muito tempo que foram capacitados, como é o caso de E4, que afirmou: "não me recordo qual o nome do curso". No que tange a cursos oferecidos pelo Prolnfo, é muito deficiente a realidade de Gurupi, porém os professores são capacitados, de acordo com as exigências legais, para atuarem no sistema de ensino municipal.

Observando o Gráfico 1 (Gráfico tipo Radar), nota-se que essa categoria aproxima-se do centro (zero), por ser a falta de participação na capacitação oferecida pelo Prolnfo a resposta da maioria dos entrevistados.

\section{Condições de infraestrutura e manutenção dos laboratórios}

A infraestrutura oferecida, em parte, atende às necessidades das escolas. Todas as escolas visitadas possuem laboratórios que satisfazem à quantidade de alunos por computador. A Prefeitura de Gurupi atende às demandas de acordo com as suas limitações, em especial as financeiras.

Segundo o entrevistado E1 (secretário municipal de Educação), "o município vem fazendo a manutenção e substituição de máquinas permanentemente". Aproximadamente $70 \%$ dos entrevistados concordam que as condições de infraestrutura são boas, como diz E2: “No Município, nós estamos de parabéns".Entretanto, há alguns que consideram que não é a mais adequada, 
como afirma E13: "Péssimos.Na verdade, nós temos computadores, mas a manutenção e o acesso não é bom". Alguns participantes também reclamam da falta de autonomia, como é o caso de E4: "Nós da escola não temos essa autonomia para mexer nas máquinas".

Ressalta-se que foi possível perceber o comprometimento de gestores e profissionais de Educação do Município de Gurupi no zelo e na conservação dos equipamentos, colocados à disposição dos professores e alunos. Todavia, como relatado na entrevista com o secretário de Educação, há algum tempo os repasses do Governo Federal são insuficientes para a manutenção dos laboratórios de maneira adequada. Diante dessa realidade, é necessário canalizar essa estrutura para os objetivos do programa, pois não basta somente ter laboratórios e não usá-los de forma a alavancar os processos de ensino e de aprendizagem.

Observando o Gráfico 1, esta categoria encontra-se entre os números 4 e 6 , o que evidencia um regular atendimento aos objetivos do programa, havendo necessidade de uma atenção do poder público municipal para aperfeiçoar esse fator nas escolas.

\section{Utilização do laboratório de informática pelos professores}

Os professores, em geral, usam os laboratórios e as ferramentas colocadas à disposição; entretanto, de acordo com relatos de alguns entrevistados, nem todos têm facilidade para utilizar a tecnologia como ferramenta pedagógica e outros não têm interesse em aprender. Um dos professores entrevistados (E3) afirmou que: "Esses mais jovens utilizam bastante o laboratório de Informática. Agora, aqueles professores que já têm muito tempo de carreira, eles ainda têm certa dificuldade no uso do laboratório", e E14 relatou que: "O laboratório, em específico, não. São bons, porém pouco explorado [sic] por nós professores".

Fazendo uma comparação entre as respostas às entrevistas realizadas com o secretário de Educação, Diretores e Professores e os questionários aplicados aos estudantes no que diz respeito ao uso da tecnologia como apoio pedagógico, percebe-se que há utilização dos computadores nas escolas por parte de alunos e professores, com oportunidades de melhorias no que tange a quantidade de horas e finalidade do uso. Contudo, ainda existe uma parcela significativa de professores que não utilizam laboratórios, estando entre os números6 e 8, conforme mostrado anteriormente no Gráfico 1. Ao se perguntar quantas vezes o aluno já utilizou o computador durante o ano letivo, tendo em vista que esta pergunta foi feita no final do primeiro semestre de 2018 , aproximadamente $60 \%$ dos alunos responderam que foram de 1 a 3 vezes e quase a totalidade respondeu que as máquinas foram usadas para a realização de uma pesquisa.

Nesta categoria foi avaliado se a escola dispõe de computadores suficientes e se disponibiliza essas máquinas para uso dos alunos; se existe internet na escola e se os professores utilizam os laboratórios para ministrarem suas aulas.

Não era nosso objetivo averiguar se realmente existia ou não internet na escola, mas buscar identificar a percepção do aluno sobre o uso da internet como apoio pedagógico, por exemplo. Pelas respostas, $83 \%$ disseram que "sim", contra $17 \%$ dos respondentes que disseram "não". Cabe destacar que geralmente as escolas têm internet, mas sem uma boa qualidade de conexão; em outros casos, 
elas têm, mas os alunos não a utilizam, ou mesmo têm, mas ora a conexão está boa, ora está ruim.

Apesar disso, a maior parte dos alunos que foram questionados sobre a utilização da internet em aulas deu respostas afirmativas, como se pode notar na Tabela 1.

Tabela 1- Durante o ano letivo, os professores já utilizaram a internet nas aulas?

\begin{tabular}{ccccc}
\hline Ano & SIM & $\%$ & NÃO & $\%$ \\
\hline 6 & 56 & $39 \%$ & 24 & $39 \%$ \\
70 & 32 & $23 \%$ & 12 & $19 \%$ \\
$8 \%$ & 15 & $10 \%$ & 9 & $15 \%$ \\
$9 \%$ & 40 & $28 \%$ & 17 & $27 \%$ \\
\hline TOTAL & 143 & $100 \%$ & 62 & $100 \%$ \\
\hline
\end{tabular}

Fonte: Elaboração própria com base nos dados coletados no questionário

Os dados apresentados na Tabela 1 são de extrema importância para os propósitos deste trabalho, pois mostram, por intermédio dos alunos dos anos finais do Ensino Fundamental de Gurupi, se os professores já utilizaram a internet nas aulas, durante o ano letivo. Como a coleta dos dados foi realizada no fim de junho de 2018, portanto já no final do semestre letivo, houve tempo suficiente para que o professor tivesse usado as tecnologias à sua disposição, no processo de ensino.

As respostas indicam que, aproximadamente, 70\% dos professores (143 de 205) já haviam utilizado a internet em suas aulas, sendo os professores do 60 ano os que mais a utilizaram, representando 39\% do total. Quarenta por cento de professores que não utilizaram a internet nesse ano letivo é um percentual relativamente alto e deve servir de alerta aos gestores do Programa. Suscita-se a questão: porque ainda não a utilizaram?

Os alunos foram indagados, ainda, se eles próprios, independentemente dos professores, haviam utilizado o computador na escola. As respostas estão no Gráfico 2. 
Gráfico 2 - Neste ano letivo, quantas vezes você utilizou o computador na escola?

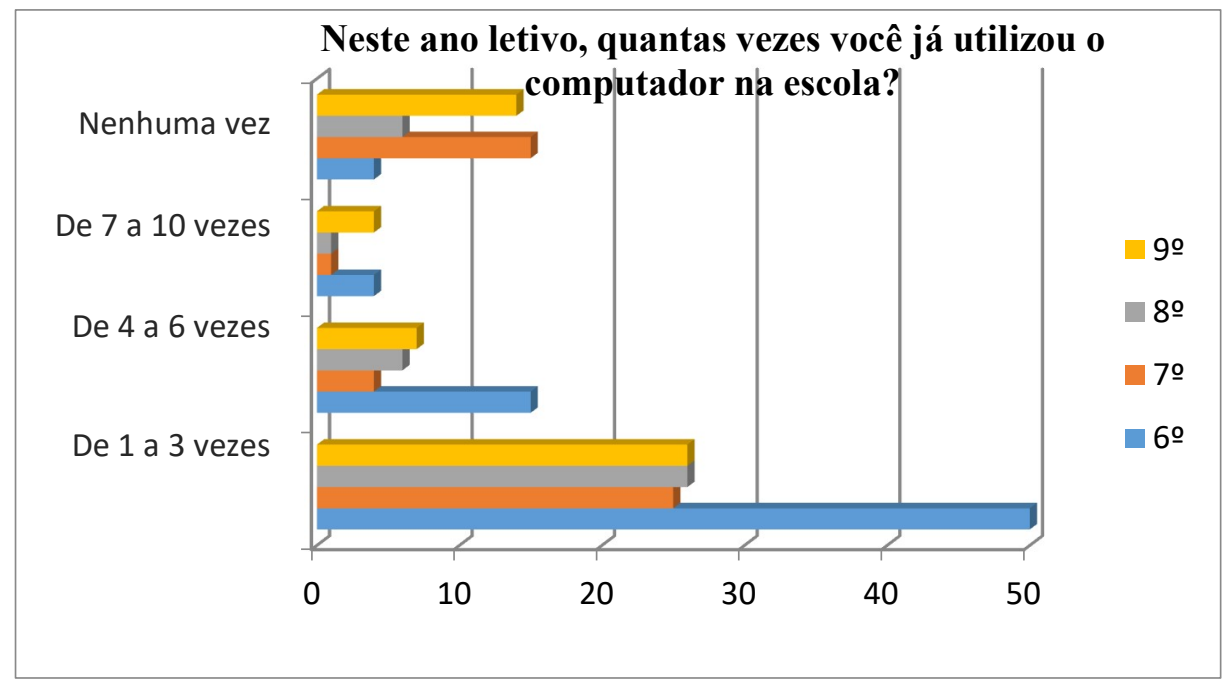

Fonte: Elaboração própria com base nos dados coletados nos questionários

Como já mencionado, a coleta de dados em campo foi realizada no fim do primeiro semestre de 2018.Supõe-se, então, que houve tempo para que o aluno tenha utilizado os computadores da escola pelo menos uma vez. Observando-se o Gráfico 2, nota-se que aproximadamente60\%dos alunos(127 de 205) do $6^{\circ}$ ao $9^{\circ}$ ano utilizaram de 1 a 3 vezes os computadores da escola, porém existem, nesses mesmos anos, muitos (aproximadamente 15\% dos alunos) que não os utilizaram nenhuma vez. Isso preocupa, pois, para que haja inclusão digital e aprendizagem com o uso dos computadores, há necessidade de maior tempo de prática.

\section{CONSIDERAÇÕES FINAIS}

Este trabalho teve o intuito de analisar a eficácia do Prolnfo, no que concerne à inclusão digital e ao apoio pedagógico, em escolas do Ensino Fundamental, nos anos finais, no Município de Gurupi (Tocantins).

Como a avaliação é um importante instrumento de políticas públicas, vale destacar a importância deste trabalho como forma de dar visibilidade ao Prolnfo no Município de Gurupi (TO) e no país, bem como aperfeiçoar o objeto avaliado, sobretudo no contexto pesquisado.

No que diz respeito à questão se o Prolnfo constitui-se em uma ferramenta de apoio pedagógico em escolas municipais de Gurupi (TO), constatou-se que estas não atendem a esse objetivo plenamente. Em primeiro lugar, porque não há cursos com a freqüência adequada para a capacitação dos professores e, em segundo lugar, porque a quantidade de horas-aula com o uso do computador na escola ainda é baixa. Apesar de os professores das escolas de Gurupi usarem os laboratórios das escolas, todavia, pelo que se infere das falas, tanto de alunos como de professores, o ensino com o apoio dos laboratórios necessita ser frequente e direcionado, pedagogicamente, para que possa refletir na melhoria do aprendizado. Ao se compararem as constatações da presente pesquisa com as conclusões das obras constantes do referencial teórico, é possível verificar que há muitos pontos em comum. As conclusões de alguns autores como Rocha (2013), 
Paiva (2014), Cerqueira (2016) e Rodrigues (2017) apontam desconhecimento por parte dos professores, deficiências no Prolnfo, insuficiência de informações, o uso das TIC de forma secundária, deficiências instrumentais, escassez de recursos, entre outros problemas encontrados em trabalhos recentes, que reforçam as conclusões deste trabalho.

A Prefeitura de Gurupi, por meio da Secretaria de Educação, procura manter as escolas em boas condições no que tange aos meios tecnológicos. Porém, falta capacitar os professores para que estes utilizem os computadores como ferramentas de apoio pedagógico, de modo a contribuir para a melhoria do aprendizado. Além disso, há resistência de alguns professores ao uso pedagógico das tecnologias, muitas vezes porque eles não dominam completamente as ferramentas.

Avaliando se o Prolnfo contribuiu para a inclusão digital de alunos do Ensino Fundamental, nos anos finais, no Município de Gurupi (TO), observou-se que os alunos ainda não têm o acesso desejado. A questão da inclusão digital tem muitos aspectos a serem considerados, pois, muitas vezes, o acesso pode ocorrer simplesmente para se realizar uma atividade de lazer ou para conversas informais em redes sociais, ou para uma atividade formal, como uma inscrição em um curso, etc.

Em Gurupi, pelo que foi relatado pelos gestores e professores, para que se utilizem os laboratórios deve haver um planejamento prévio por parte dos professores, o que parece ser justo, pois as atividades escolares têm objetivos pré-definidos e planejados. Em contrapartida, a falta de livre acesso dos alunos e professores aos laboratórios de Informática acaba dificultando o uso dos computadores. Dessa forma, entende-se que o quesito inclusão digital, de uma forma geral, não é atendido plenamente, apesar da existência de ações capazes de contribuir para a ampliação do acesso.

Ficou evidenciado que o Município dispõe dos recursos tecnológicos, ou seja, laboratórios com computadores, mesmo que às vezes não tão modernos, que são colocados à disposição das escolas. Porém, de modo geral, os meios colocados à disposição não são utilizados de maneira a atender, plenamente, aos objetivos originais do Programa, por falta ou insuficiência de cursos de Informática, sobretudo para os professores.

Diante dessa realidade, considerou-se que o Município implementou parcialmente os objetivos do Prolnfo. Esforços têm sido empreendidos, mas ainda há necessidade de aperfeiçoamento no processo de implementação do Programa.

É preciso reorganizar e direcionar a utilização do Prolnfo como ferramenta pedagógica, com o comprometimento da gestão municipal e da comunidade escolar, para que o programa possa, de fato, refletir nos processos de ensino e de aprendizagem. Faz-se urgente a inclusão digital, com a utilização frequente das tecnologias, por parte de professores e alunos, de modo a tornar cada escola em um centro disseminador de informação e conhecimento.

Diante do exposto, ao se analisar a eficácia do Prolnfo no Município de Gurupi (TO), é possível concluir que o Programa está sendo parcialmente eficaz, pois não cumpre, plenamente, os seus objetivos originais, a saber: proporcionar a inclusão digital e servir de ferramenta de apoio pedagógico. 


\title{
Public education policies: an analysis of the effectiveness of the national program of educational technology (Proinfo) in the municipality of Gurupi (TO)
}

\begin{abstract}
This work aims to analyze the effectiveness of the National Program of Educational Technology (Prolnfo), regarding digital inclusion and pedagogical support, in Elementary schools, in the final years, in the Municipality of Gurupi (Tocantins). The methodological approach adopted in this work is the qualitative and quantitative. Data collection was carried out through the application of questionnaires to a sample of students from the 6th to the 9th year of elementary school and semi-structured interviews with the secretary of Education, teachers and directors of six schools in the municipality of Gurupi. In assessing the effectiveness of Prolnfo in the municipality of Gurupi (TO), it was possible to conclude that the Program is being partially effective, as it does not fully meet its original objectives, namely to provide digital inclusion and to serve as a pedagogical support tool.
\end{abstract}

KEYWORDS: Prolnfo. Evaluation of Public Policies. Elementary School 


\section{REFERÊNCIAS}

BARDIN, L. Análise de conteúdo. São Paulo: Edições 70, 2011.

BRASIL.Constituição da República Federativa do Brasil de 1988. Brasília, DF: Presidência da República, [2018]. Disponível em:

<http://www.planalto.gov.br/ccivil_03/constituicao/constituicao.htm>. Acesso em: 2 jun. 2014.

BRASIL. Lei $n^{\circ} 9.394$ de 20 de dezembro de 1996. Estabelece as Diretrizes e Bases da Educação Nacional. Diário Oficial da União: seção 1, Brasília, DF, p. 27.833, 20 dez. 1996.

BRASIL. Lei n. 12.249, de 11 de junho de 2010. Brasília, DF: Presidência da República,2010. Disponível em: <https://www.fnde.gov.br/programas/programanacional-de-tecnologia-educacional-proinfo/proinfo-programa-um-computadorpor-aluno-prouca>. Acesso em:20 mar. 2018.

BRASIL. Ministério da Educação. Decreto no 6.300, de 12 de dezembro de 2007. Dispõe sobre o Programa Nacional de Tecnologia Educacional - Prolnfo. Diário Oficial da União: seção 1, Brasília, DF, p. 3, 13 dez. 2007.

BRASIL. Ministério da Educação. Diretrizes Curriculares Nacionais da Educação Básica.Brasília: Ministério da Educação, 2013.

BRASIL. Ministério da Educação. Portaria no 522,de 9 de abril de 1997. Cria o Programa Nacional de Informática na Educação. Brasília, DF: Ministério da Educação, 1997a. Disponível em:<http://www.dominiopublico.gov.br/pesquisa/DetalheObraForm.do?select_a ction=\&co_obra=22148>. Acesso em: 13 mar.2018.

BRASIL. Ministério da Educação. Prolnfo:diretrizes. Brasília, 1997b. Disponível em:

$<$ http://www.dominiopublico.gov.br/pesquisa/DetalheObraForm.do?select_actio n=\&co_obra=22147>. Acesso em: 13 mar.2018.

BRASIL. Ministério da Educação. Prolnfo- Apresentação.Brasília. Disponível em<http://portal.mec.gov.br/proinfo/proinfo>. Acesso em: 13 mar.2018.

CÂMARA, R. H. Análise de conteúdo: da teoria à prática em pesquisas sociais aplicadas às organizações. Gerais: Revista Interinstitucional de Psicologia, v. 6, n. 2, p. 179-191,2013.

CASTELLS, M.; CARDOSO, G. (org.). A Sociedade em Rede: do conhecimento à ação política. Conferência. Belém: Imprensa Nacional, 2005.

CASTELLS, M. Sociedade em Rede:A Era da Informação: economia, sociedade e cultura, v. 1.São Paulo: Paz e Terra, 1999.

CERQUEIRA, Luis Alberto Menezes. Panorama de política pública federal de integração entre escolas públicas e TIC: estudos sobre PROINFO, Prouca, PBLE. 
2016. 118 f. Dissertação (Mestrado em Educação) - Faculdade de Educação, Universidade do Estado do Rio de Janeiro, Rio de Janeiro, 2016.

COHEN, E.; FRANCO, R. Avaliação de projetos sociais.2. ed. Petrópolis, Rio de Janeiro: Vozes,1998.

DA SILVA, M. L. G. A Inclusão Digital nas Políticas Públicas de Inserção das Tecnologias de Informação e Comunicação na Educação: o discurso e a prática dos cursos de formação de Professores. 2014. Dissertação (Mestrado em Educação) - Faculdade de Educação, Universidade Federal da Bahia, Salvador, 2014.

GONÇALVES, L. M. Mudanças nas concepções e ações docentes: processo de integração de computadores portáteis ao currículo. 2015. Tese (Doutorado em Educação)-PUCSP, São Paulo, 2015.

LÉVY, P. As tecnologias da inteligência. São Paulo: 34, 1997.

LÉVY, P. Cibercultura. São Paulo: 34, 1999.

CARVALHO, C. V. de A.et al. A Integração da TIC na Escola Básica: Questões para Avaliação. Teccen, Vassouras, Rio de Janeiro, v. 1, n. 1, 2008.

MINAYO, M. C. de S. (org.). Pesquisa social: teoria, método e criatividade. Rio de Janeiro: Vozes, 2001.

MITCHELL, W.J. E-topia:a vida urbana - mas não como a conhecemos. São Paulo: SENAC, 2002.

MORAES, M. C. Informática educativa no Brasil: uma história vivida, algumas lições aprendidas. Revista Brasileira de Informática na Educação, Florianópolis, n. 1, 1997.

PAIVA, Vânia de Fátima Flores. Um Olhar Sobre a Implantação do PROINFO em Escolas Municipais de Minas Gerais. Dissertação. (Mestrado) - Universidade Federal de Lavras, Programa de Pós-Graduação Profissional em Educação, área de concentração em Formação de Professores, Lavras-MG, 2014.

ROCHA, Maria das Vitórias Ferreira. Avaliação de política pública: o PROINFO e sua gestão no município de parnamirim-RN (2009-2012). Dissertação.

(Mestrado) - Programa de Pós-Graduação em Ciências Sociais. Universidade Federal do Rio Grande do Norte, Natal, 2013.

RODRIGUES, AntoniaZeneide. Inclusão Digital e Educação: Uma Avaliação do PROINFO em Sobral/CE. Dissertação. (Mestrado) - Programa de Pós-Graduação em Ciências Sociais. Universidade Federal do Rio Grande do Norte, Natal, 2017.

WAISELFISZ, J. J. Lápis, borracha e teclado: tecnologia da informação na educação - Brasil e América Latina. Brasília, DF: Rede de Informação Tecnológica Latino-Americana (RITLA), 2007. Disponível em <https://www.mapadaviolencia.org.br/publicacoes/lapis_borracha_teclado.pdf>. Acesso em: 13 mar.2018. 
Recebido: 24/03/2019

Aprovado: $12 / 02 / 2020$

DOI: $10.3895 /$ rts.v16n42.9889

Como citar: RODRIGUES, R.N.; SILVA, M.A.R. Avaliação de políticas públicas de educação: uma análise da eficácia do programa nacional de tecnologia educacional (Proinfo) no município de Gurupi (TO).

R. Tecnol. Soc., Curitiba, v. 16, n. 42, p. 123-139. jul/set. 2020. Disponível em:

https://periodicos.utfpr.edu.br/rts/article/view/9889 .Acesso em: XXX.

Correspondência:

Direito autoral: Este artigo está licenciado sob os termos da Licença Creative Commons-Atribuição 4.0 Internacional.

\section{(c) (1)}

